\title{
Unmet Need for Family Planning and Associated Factors Among Married Women in Asebot Town, West Hararge Zone, Oromia Regional State, Ethiopia, Cross- Sectional Study Design, 2018
}

\author{
Ismael Kalayu*, Misganaw Muche, Muhammedawel Kaso and Amde Eshete \\ Department of Public health, University of Arsi, Ethiopia
}

Submission: June 11, 2019; Published: July 24, 2019

*Corresponding author: Ismael Kalayu, Department of Public health, University of Arsi, college of health sciences, Assela, Ethiopia

Abstract

Background: Unmet need for family planning was one of the several frequently used indicators for monitoring and evaluation of family planning programs. It also helps to identify women at greatest risk of unintended pregnancy for satisfying the unmet need for modern contraception. So, this study aimed to assess the prevalence and associated factors of unmet need for modern contraceptive among women of reproductive age in Asebot town, west Harargie zone, Oromia Regional state, Ethiopia.

Methods: A community based cross-sectional study design was conducted in Asebot town. Systematic random sampling techniques were used to select 410 reproductive age women. Data collection was carried out from July 19 to August 05, 2018 using a pre- tested structured questionnaire. The collected data were entered to Epi-info version 7 and exported to SPSS version 21 for analysis. Candidate variables with p-value of $<0.25$ in bivariate analysis were entered into multivariable logistic regression and AOR at $95 \% \mathrm{CI}$ with p-value of $<0.05$ was considered as significant.

Result: The magnitude of unmet need for modern family planning in the study area was $37.3 \%$. [95\% CI $(32.7,42.2)]$. After multivariate analysis Age, monthly income, desire to have children within two years and partner approval of family planning use were statistically significantly associated factors of unmet need for family planning with their $95 \% \mathrm{CI}$ as follows (2.00-39.83), (1.10-6.10), (4.79-15.67), (3.88-14.61) respectively.

Conclusions: Since the magnitude of unmet need for family planning in this study was very high, and a community problem, so that Oromia regional health bureau and West Hararghe zonal health bureau should increase their efforts in order to reduce this high rate of unmet need for family planning by due emphasis on those factors contributing for unmet need for family planning.

Keywords: Unmet need, Family planning, West Hararge, Ethiopia, Asebot town

Abbreviations: AOR: Adjusted Odds Ratio; CBRH: Community Based Reproductive Health; CSA: Central Statistical Agency; CPR: Contraceptive Prevalence Rate; EDHS: Ethiopian Demographic And Health Survey; EMONC: Emergency Obstetrics And Newborn Care; EPI Info: Epidemiological Information; FP: Family Planning; FGD: Focus Group Discussion; HC: Health Center; HHS: Households; IUD: Intra Uterine Device; KAP: Knowledge Attitude And Practice; MDG: Millennium Development Goal; OR: Odds Ratio; SPSS: Statistical Package For Social Science; SSA: Sub Saharan Africa; Tl: Tubal Ligation; WHO: World Health Organization.

\section{Introduction}

Unmet need for family planning refers to fecund women who either wish to postpone the next birth (spacers) or wish to stop childbearing (limiters) but are not using a contraceptive method [1,2]. Worldwide; over 222 million women have unmet need for contraception [3] and around 137 million women in the developing world who would like to avoid childbearing are unable to do so; despite a huge increase in contraceptive access and use globally [4]. Many women in low and middle-income countries would like to limit or delay getting pregnant; but do not have access to consistent use of modern contraceptive methods $[5,6]$.

Unintended pregnancy related to unmet need is a worldwide problem that affects women and their families and societies at large [7]. And it is a serious public health issue both in developed and developing countries [8]. The high level of unmet need in family planning is potential for high unwanted pregnancies [9]. 
Rates of unmet need for family planning remain highest among developing countries where one in every four women in their reproductive age remain exposed to unintended pregnancies or are unable to postpone childbirth [10]. Increasing contraceptive demand; access; and uptake are key interventions to improve maternal health outcomes and ultimately reduce maternal deaths [11]. In Ethiopia; fertility rates and unmet need for family planning have traditionally been very high [12].

Achievement of desired number and healthy timing of births have important benefits for women; families; and societies [13]. Unmet need for family planning is a valuable concept that is widely used for advocacy; development of family planning policies; implementation and monitoring of family planning programs worldwide [14]. Therefore; conducting research regarding unmet need for family planning is mandatory to carry an intervention to prevent the consequence of unplanned pregnancies due to unmet need for family planning.

\section{Methods and Materials}

\section{Study area; Study design and period}

The study was conducted in Oromia region; Asebot town. It was located at about $291 \mathrm{~km}$ East of Addis Ababa with the total population of 27,300 as projected of 2017 CSA report of which females were 13,377. Among the total population 6,033 were in the reproductive age group expected to use contraceptive method. It has one local administrative kebele and six ketena. The health facilities available in the town were one hospital; one health center; one health post; which were public and has 5 clinics of different levels owned by private. A community based cross-sectional study design was used from July 19 to August 05;2018.

\section{Sample size determination}

Was determined using the formula for single population proportion; using the following assumptions; the prevalence of unmate need $41.5 \%$ taken from study conducted on Arbaminch [15]; confidence level 95\%;standard Z-score 1.96;marginal error 0.05 and adding $10 \%$ non-response rate the final sample size was $: 410$.

\section{Sampling procedures}

Households were selected by systematic random sampling technique with K value of 8 (N: 3330 and n: 410 (N/n:3330/410:8 i.e. every 8 house). The first house was selected by lottery method. For households which do not fulfill inclusion criteria the next household was selected. And if no women available in the selected household; we repeatedly saw her at least three times. The calculated 410 sample was proportionally allocated to the ketenes based on the total number of households with women of reproductive age.

\section{Data collection tools and procedures}

Data was collected using pre-tested; structured questionnaire; which developed by reviewing WHO; EDHS tools and other literatures in order to address the objective of the study. Six data collectors (BSc nurses) and two supervisors (BSc in Health officer); Afan Oromo speakers was selected from the woreda (other than the selected town for the survey). The investigator was provided to all enumerators and supervisor for two days on objective and methodology of the research; data collection and interviewing approach and data recording.

The questionnaire was pre-tested in $10 \%$ of the questionnaire respondents having similar characteristics from the study area which was not included in this study. Based on the pre-test result; adjustments were made to the questionnaire. Then households with reproductive age women were selected by using simple random sampling technique. Finally; reproductive age women in the selected household were interviewed. From households who do have more than two reproductive age women lottery method was used to select one study participant.

\section{Data quality assurance and analysis}

The questionnaire was prepared originally in English and translated to Afan Oromo and back to English by language experts to keep the consistency of the question. Training was given for data collectors and supervisors. The investigator together with supervisor checked and reviewed questionnaires on daily bases to ensure completeness and consistency of information collected. Quantitative data was entered; cleaned and edited using EPI INF 7 statistical software and then exported to SPSS version 21 for analysis. The descriptive statistics of the collected data was done for most variables in the study using statistical measurements. Frequency; tables; graphs; percentages; means and standard deviations was used.

Frequency distribution was done for categorical data. Binary logistic regression analysis was conducted primarily to check which variables have association with the dependent variables individually. Variables having $\mathrm{P}$ value $\leq 0.25$ in the bi-variable binary logistic regression analysis was entered into multivariable binary logistic regression analysis for controlling the possible confounders and finally the variables which have significant association was identified with $95 \% \mathrm{CI}$ and $<0.05$ p-values.

\section{Result}

\section{Socio-demographic characteristics of the study population}

A total of 410 reproductive age women from Asebot town were included in a study with a response rate of $100 \% .54 .6 \%$ of them were between 28 -38 years with mean age of $31.98( \pm 6.07$ SD). $70.7 \%$ were Muslim while $75.1 \%$ of them were Oromo; and $63.9 \%$ of them were housewife. About one third (35.1\%) of the respondents and $22.9 \%$ of their husbands were illiterate; $40.7 \%$ of the participants' monthly income were between 1501.00 - 3000.00 birr and almost all has access to media (Table 1). 3.2 Reproductive health characteristics of the study population. 
Table 1: Socio- demographic characteristics of reproductive age women in Asebot town, West Haragie, Oromia, Ethiopia, October 2018. $(\mathrm{N}=410)$.

\begin{tabular}{|c|c|}
\hline Variable & Frequency (\%) \\
\hline \multicolumn{2}{|c|}{ Current mother age } \\
\hline $17-27$ & $35(8.5)$ \\
\hline $28-38$ & $224(54.6)$ \\
\hline $39-49$ & $151(36.9)$ \\
\hline \multicolumn{2}{|c|}{ Religion } \\
\hline Orthodox & $96(23.4)$ \\
\hline Muslim & $290(70.7)$ \\
\hline Protestant & $22(5.4)$ \\
\hline Catholic & $2(0.5)$ \\
\hline \multicolumn{2}{|l|}{ Ethnicity } \\
\hline Oromo & $308(75.1)$ \\
\hline Somali & $18(4.4)$ \\
\hline Amhara & $56(13.7)$ \\
\hline Guragie & $28(6.8)$ \\
\hline \multicolumn{2}{|c|}{ Educational status of women } \\
\hline Can't read and write & $144(35.1)$ \\
\hline Can read and write & $97(23.7)$ \\
\hline Primary & $94(22.9)$ \\
\hline Secondary & $64(15.6)$ \\
\hline Above 12 & $11(2.7)$ \\
\hline \multicolumn{2}{|c|}{ Occupation of the women } \\
\hline Housewife & $262(63.9)$ \\
\hline Farmer & $21(5.1)$ \\
\hline Merchant & $79(19.3)$ \\
\hline employee & $47(11.5)$ \\
\hline Daily laborer & $1(0.2)$ \\
\hline \multicolumn{2}{|c|}{ Educational status of husband } \\
\hline Can't read and write & $94(22.9)$ \\
\hline Can read and write & $137(33.4)$ \\
\hline Primary & $61(14.9)$ \\
\hline Secondary & $49(12.0)$ \\
\hline Above 12 & $69(16.8)$ \\
\hline \multicolumn{2}{|c|}{ Average monthly income } \\
\hline$\leq 1500$ & $80(19.5)$ \\
\hline $1500-3000$ & $167(40.7)$ \\
\hline$>3000$ & $163(39.8)$ \\
\hline \multicolumn{2}{|c|}{ Owning of Media access } \\
\hline Radio only & $369(90)$ \\
\hline TV only & $38(9.3)$ \\
\hline Print media & $3(0.7)$ \\
\hline
\end{tabular}

$99 \%$ of the respondents were ever been pregnant of which $98.8 \%$ were ever giving birth and $2.2 \%$ were currently pregnant. One hundred thirty-seven (32.4\%); One hundred forty (34.1\%) and One hundred thirty-two (32.2\%) women had 1-2;3-4 and $\geq 5$ total living children respectively. Majority of respondents $335(81.7 \%)$ of women wish to have more than 5 children in their life and majority $314(76.6 \%)$ states family planning service was free of charge (Table 2).

Table 2: Reproductive health characteristics of women, in Asebot town, West Harargie zone, Oromia, Ethiopia, October $2018(n=410)$.

\begin{tabular}{|c|c|}
\hline \multicolumn{2}{|c|}{ Characteristics at ${ }^{\text {st }}$ marriage } \\
\hline$\leq 18$ & $123(30)$ \\
\hline$>18$ & $287(70)$ \\
\hline \multicolumn{2}{|c|}{ Number of pregnancies } \\
\hline$\geq 5$ & $75(18.3)$ \\
\hline \multicolumn{2}{|c|}{ Number of alive children } \\
\hline $1-2$ & $133(32.4)$ \\
\hline $3-4$ & $140(34.1)$ \\
\hline$\geq 5$ & $137(33.5)$ \\
\hline \multicolumn{2}{|c|}{ Total children wish to have } \\
\hline $1-2$ & $4(1)$ \\
\hline $3-4$ & $82(20)$ \\
\hline$\geq 5$ & $324(79)$ \\
\hline \multicolumn{2}{|c|}{ Family planning service cost } \\
\hline Affordable & $22(5.3)$ \\
\hline Free & $314(76.6)$ \\
\hline No idea & $74(18)$ \\
\hline
\end{tabular}

Current contraceptive use pattern of the study population

About two-third $62.7 \%$ of the respondents were using contraceptive methods at time of survey. Among current users; $60.7 \%$ and $2 \%$ were using family planning for spacing and limiting respectively. The most commonly used methods were; Implant $78.3 \%$; followed by Injectable $74.6 \%$ (Table 3).

Table 3: Reproductive health characteristics of women, in Asebot town, West Harargie zone, Oromia, Ethiopia, October $2018(n=410)$.

\begin{tabular}{|c|c|}
\hline variables & Frequency (\%) \\
\hline Use contraceptive for spacing & $249(60.7)$ \\
\hline Use contraceptive for limiting & $9(2)$ \\
\hline Were used Implant & $321(78.3)$ \\
\hline Were used Injectable & $306(74.6)$ \\
\hline
\end{tabular}

\section{Reasons for not Using family planning methods}

The reasons of not using family planning were being pregnancy $9(2.2 \%)$; fear of side effects $10(2.4 \%)$; due to breast feeding 17(4.1\%); desire of child 78(19\%) and other reasons like religious prohibition 39(9.5\%) (Table 4).

\section{Family planning utilization related characteristics}

Concerning the knowledge level of the respondents; majority $99.51 \%$ of the respondents know oral contraceptive pills; $98.78 \%$ 


\section{Global Journal of Reproductive Medicine}

know injectable;96.59\% know implants; and 92.44\% know Intra uterine contraceptive device (IUCD) but almost the whole respondents do not know permanent family planning method such as Tubal Ligation (TL) and Vasectomy. Three hundred five (74.4\%) reported; they know that the sources of modern FP were health facility of these; $92.9 \%$; and $15.1 \%$ of the respondents mentioned government facilities and private clinics respectively as the source of modern FP. Respondents got information about family planning from Radio 90\% followed by TV 9.3\%.

Table 4: Reasons for not using Family planning methods among reproductive women in Asebot town, West Harargie Zone, Oromia, Ethiopia, October 2018.

\begin{tabular}{|cc|c|}
\hline Variables & \multicolumn{2}{c|}{ Frequency (\%) } \\
\hline \multicolumn{3}{|c|}{ Lack of knowledge } \\
\hline Yes & $353(86.1)$ \\
\hline No & $57(13.9)$ \\
\hline Yes & \multicolumn{2}{|c|}{$380(92.7)$} \\
\hline No & $30(7.3)$ \\
\hline \multicolumn{3}{|c|}{ To get pregnant } \\
\hline Yes & $404(98.5)$ \\
\hline No & $6(1.5)$ \\
\hline \multicolumn{2}{|c|}{ Cultural taboo } \\
\hline Yes & $370(90.2)$ \\
\hline No & $40(9.8)$ \\
\hline
\end{tabular}

\section{Factors associated with unmet need for family planning}

Bivariate analysis was done to see the association between the dependent and independent variables. Later; controlling possible confounders; multivariate analysis has shown that monthly income; desire to have children in 2 years; partner approval to use family planning and age had statistically significantly associated with unmet need for family planning.

Among the respondents; age between 28 to 38 years were 9 times more likely to have unmet need as compared to respondents whose age category was 17 to 27;[AOR: 8.92;95\% CI: 2.00;39.83] and respondents with 39-49 years of age were 5 times more likely to have unmet need compared to 17 to 27 years of age;[AOR: 5.23;95\% CI: 1.09;25.12]. Concerning to respondent's income; respondents who have family income of less than 1500 birr were 2.6 times more likely to have unmet need for family planning as compared to respondents whose income was more than 3000 birrs; [AOR: 2.59;95\% CI: 1.10;6.10]. Respondents who have no desire to have children within two years were 8.7 times more likely to have unmet need compared with respondents who have desire to have children within two years; [AOR: 8.66;95\% CI: $4.79 ; 15.67]$. Respondents who have no approval of using family planning services by their partner were 7.5 times more likely to have unmet need for family planning as compared to respondents who have partner approval; [AOR: 7.53;95\% CI: 3.88;14.61] (Table 5).

Table 5: Factors associated with unmet need of family planning among women reproductive age group in Asebot town, 2018.

\begin{tabular}{|c|c|c|c|c|}
\hline \multirow{2}{*}{ Variable } & \multicolumn{2}{|c|}{ Unmet need for family planning } & \multirow{2}{*}{ COR $(95 \% \mathrm{CI})$} & \multirow{2}{*}{ AOR (95\%CI) } \\
\hline & Yes & No & & \\
\hline \multicolumn{5}{|c|}{ Monthly income } \\
\hline$<1500$ & 46 & 34 & $3.05(1.75-5.32)$ & $2.59(1.10-6.10)^{* * *}$ \\
\hline $1501-3000$ & 57 & 110 & $1.17(0.73-1.85)$ & $1.25(0.14-0.82)$ \\
\hline$>3000$ & 50 & 113 & 1 & 1 \\
\hline \multicolumn{5}{|c|}{ Desire to have child in $2 y r s$} \\
\hline No & 121 & 66 & $10.94(6.77-17.67)$ & $8.67(4.79-15.67)^{* * *}$ \\
\hline Yes & 32 & 191 & 1 & 1 \\
\hline \multicolumn{5}{|c|}{ Discuss FP with your partner } \\
\hline Yes & 80 & 55 & $4.02(2.60-6.22)$ & $1.82(0.89-3.71)$ \\
\hline No & 73 & 202 & 1 & 1 \\
\hline \multicolumn{5}{|c|}{ Age of the respondents } \\
\hline $17-27$ & 4 & 31 & 1 & 1 \\
\hline $28-38$ & 96 & 128 & $0.172(0.079-0.71)$ & $5.55(1.40-21.87)^{* * *}$ \\
\hline $39-49$ & 53 & 98 & $1.38(0.91-2.12)$ & 4.17 (0.97 - 17.99) \\
\hline \multicolumn{5}{|c|}{ Parity } \\
\hline$<5$ & 107 & 206 & $0.57(0.36-0.91)$ & $0.39(0.14-1.12)$ \\
\hline$\geq 5$ & 46 & 51 & 1 & \\
\hline \multicolumn{5}{|c|}{ Partner approval } \\
\hline No & 25 & 168 & $9.66(5.86-15.92)$ & $7.53(3.88-14.61)$ \\
\hline Yes & 128 & 89 & 1 & 1 \\
\hline
\end{tabular}




\section{Global Journal of Reproductive Medicine}

\begin{tabular}{|c|c|c|c|c|}
\hline \multicolumn{5}{|c|}{ Number of alive children } \\
\hline $1-2$ & 34 & 99 & $0.54(0.32-0.92)$ & $3.27(0.96-11.1)$ \\
\hline $3-4$ & 66 & 74 & $1.41(0.87-2.27)$ & $2.17(0.77-6.11)$ \\
\hline$\geq 5$ & 53 & 84 & 1 & 1 \\
\hline
\end{tabular}

\section{Discussion}

Family planning has been one of the most broadly discoursed concepts in recent years around the world. While real progress has been made in improving access to family planning globally; the unmet needs of family planning that is; the number of individuals who would like to use family planning methods but do not have access to a full range of modern contraceptives and information continues to grow. Thus; the aim of the current study was to determine the magnitude of unmet need of family planning and its associated factors.

The magnitude of unmet need for family planning among reproductive age women from the current study was $37.3 \%$. This finding was higher than from Ethiopian Demographic and Health survey (EDHS 2016); and form studies conducted in different areas such as Oromia; Awi zone; Shire; Butajira; Nigeria [16-21]. These differences might be because this research was conducted in small town compared to the above. And the other possible reason for the observed variation in the prevalence could be due to the definition of unmet need; research design and it may also be because of recall bias as all reproductive age women were asked about their FP related experiences in this research.

However; the findings of this research were lower than similar studies conducted in Dessie; Jimma and Nepal [22-24] respectively. This variation might be due to the difference in study population; expansion of health facilities; improved access of health services and awareness of people on modern contraceptives; and availability of method choice and time. After multivariate logistic regression age; monthly income; partner approval of family planning use and desire to have children within two years were independent predictors of unmet need for FP.

Thus; from this study; respondents who were in the age group of 28-38 years had 5.5 times more likely to have unmet need as compared to women in the age group of 17-27 years. Similar finding was observed in other studies conducted in Shire; Lesotho and Kenya $[19,25,26]$. This may be because as the age of the mother increases; she might have more children and might want to limit or postpone her pregnancy. Therefore; this finding was supported from the descriptive explanation of the current finding as it is showed about $91.5 \%$ of the respondents was above the age of 28 years and $75 \%$ of them have three or more children. Another possible explanation could be as a woman's gets older; the probability of having more children will be higher and this in turn could have a negative impact on their financial access for family planning. This finding was contradicted with other findings/ studies done in Ethiopia and India in which prevalence of unmet need was significantly higher in younger age group [27,28].
Another predictor variable which affect the dependent variable was monthly income of the family. And from this study the finding revealed that those respondents who do have higher monthly income were more likely to use family planning than those respondents who do have lower monthly income. because as income increases; the families' access to information also increases. On the other hand; as women's income increase a woman's autonomy increases and improving financial decision making within a household.

This can contribute to an increase in the uptake of FP and thus in a reduction in unmet need. This finding was supported by studies in different areas such as Kenya; Uganda; India; Zambia; and Eritrea [26 \& 29-32] which showed that women who were poorer tend to have higher unmet need. The other possible reason could be women from lower socio-economic status were less likely to have educational access which in turn affect the right and the power to choose method use.

The role of men in decision making has been instrumental in traditional patriarchal societies like Ethiopia. Partner support to family planning was important predictors because men decide almost in every aspect of life including reproductive health service choices. It could also be husband wife communications on family planning provides an enabling environment for women to implement their fertility desires and contraceptive needs and men's involvement in family planning method use has also showed significant association with unmet need for family planning in studies done in Lesotho; Awi Zone and Enemay district [25,18,33]. But the present finding showed partner support for family planning was not statistically significant to unmet need.

\section{Conclusion}

The overall prevalence of unmet need for FP was high; age; monthly income; partner approval of family planning use and desire to have children within two years were independent predictors of unmet need for FP in the study area. The West Hararghe zonal health bureau should increase their efforts in order to reduce this high rate of unmet need for family planning by due emphasis on those factors contributing for unmet need for family planning.

Based on the findings of this research the following recommendation was given. Encouraging communication between reproductive age group couples and involving men more in family planning were the keys to improve unmet need. The regional and federal government has to work to increase the economic status of women. Health care workers should promote appropriate and active IEC programs that address provision of accurate information about availability of the services and various contraceptive 


\section{Global Journal of Reproductive Medicine}

options. Further researchers should be conducted to identify the extent of unmet need of different population groups; Including unmarried women and couples together.

\section{Ethical consideration}

Ethical clearance was obtained from Arsi University; Department of Public Health and the local authorities were informed about the study objectives through a letter from Arsi University; Collage of Health Science to study woreda and kebele administration offices to enhance cooperation. Verbal consent was taken from each selected participant to confirm willingness. Honest explanation of the survey purpose; description of the benefits and an offer to answer all inquiries was be made to the respondents. In addition; affirmation that they were free to withdraw consent and to discontinue participation without any form of prejudice was made. Privacy and confidentiality of collected information was ensured throughout the process.

\section{Acknowledgement}

We would like to thank the Department of Public Health; College of Health Science of Arsi University for giving this research opportunity. Our deepest thanks also go to Mieso woreda health office; Asebot Health center staffs; the populations of study site; data collectors; supervisors and study participants who were providing Us with the necessary information. Last but not the least we extend our deepest gratitude to all our families and friends who had contributions to the success of our work.

\section{References}

1. Paudel IS, Budhathoki SS (2011) Unmet needs for family planning in Sunsari, eastern Nepal 9(3): 148-151.

2. Chaudhury, Rafiqul Huda (2001) Unmet Need for Contraception in South Asia: Levels, Trends and Determinants. Asia-Pacific Population Journal 16: 3.

3. Wafula, Sam W (2015) Regional differences in unmet need for contraception in Kenya: insights from survey data. BMC Women's Health 15: 86

4. Hameed Waqas, Azmat Syed Khurram, Bilgrami Mohsina (2011) Determining the factors associated with Unmet need for family planning: a cross-sectional survey in 49 districts of Pakistan. PJPH 1(1).

5. Wulifan Joseph K, Jahn, Albrecht, Hien, Hervé, et al. (2017) Determinants of unmet need for family planning in rural Burkina Faso: a multilevel logistic regression analysis. BMC Pregnancy and Childbirth 17(1): 426.

6. Ali AA, Okud A (2013) Factors affecting unmet need for family planning in Eastern Sudan. BMC Public Health 13: 102.

7. Genet Ewnetu, Abeje Gedefaw, Ejigu Tadese (2015) Determinants of unmet need for family planning among currently married women in Dangila town administration, Awi Zone, Amhara regional state; a cross sectional study. Reproductive Health12: 42.

8. Bishwajit Ghose, Tang Shangfeng, Yaya Sanni (2017) Unmet need for contraception and its association with unintended pregnancy in Bangladesh. BMC Pregnancy and Childbirth17: 186.

9. Pahlawaniati Evi, Prasetyo Sabarinah B (2015) Socio-demographic Characteristics of Unmet Need for Family Planning in Maluku, in the 3rd International Meeting of Public Health and the 1st Young Scholar Symposium on Public Health. KnE Life Sciences 102-112.
10. Nyauchi Benard, Omedi Gilbert (2014) Determinants of Unmet Need for Family Planning among Women in Rural Kenya. African Population Studies 28: 2.

11. Austin Anne (2015) Unmet contraceptive need among married Nigerian women: an examination of trends and drivers. Contraception 91(1): 31-38.

12. Asnake Mengistu, Henry Elizabeth G, Tilahun Yewondwossen (2013) Addressing unmet need for long-acting family planning in Ethiopia: Uptake of single-rod progestogen contraceptive implants (Imp anon) and characteristics of users. Int J Gynaecol Obstet 123: e29-e32.

13. Oginni Ayodeji Babatunde, Ahonsi Babatunde Aloysius, Adebajoa Sylvia (2015) Trend and Determinants of Unmet Need for Family Planning Services among Currently Married Women and Sexually Active Unmarried Women Aged 15-49 in Nigeria (2003-2013). African Population Studies 29: 1.

14. Singh Srishti, Kalhan Meenakshi, Malik JS (2018) Assessment of unmet need for family planning and its determinants in a rural block of Haryana. Int J Community Med Public Health 5(5): 1968-1973.

15. Shifa GT, Kondale M (2014) High Unmet Need for Family Planning and Factors Contributing to it in Southern Ethiopia: A Community Based Cross-Sectional Study. Global Journal of Medical Research 14: 4.

16. Central Statistics Agency (2016) Ethiopia Demographic and Health Survey. Addis Ababa, Ethiopia. CSA and ICF.

17. Bedhadha ST (2016) Determinants of Unmet Need for Contraception among Currently Married Women in Oromia. International Journal of Science and Research 5: 12.

18. Genet E, Abeje G, Ejigu T (2015) Determinants of unmet need for family planning among currently married women in Dangila town administration, Awi Zone, Amhara regional state; a cross sectional study. Reproductive Health. BioMed Central 12: 42.

19. Gebre G, Birhan N, Gebreslasie K (2015) Unmet need for family planning in Shire-Enda- Slassie, Northern West of Tigray, Ethiopia a community based cross-sectional study. Pan African Medical Journal

20. Mekonnen, Worku (2011) Determinants of low family planning use and high unmet need in Butajira District, South Central Ethiopia. Reproductive Health 8: 8-37.

21. Fagbamigbe Francis A, Idemudia SE (2015) Demand and Unmet needs of Contraception among sexually active in-union women in Nigeria: Distribution, Drivers, Barriers, Issues and Program Implication.

22. Masresha Tegegn M, Arefaynie M, Tenaw YT (2017) Adolescent reproductive health service officer, family guidance association of Ethiopia (FGAE) North East area office, Dessie, Ethiopia. Public health department, college of medicine and health sciences, Wollo University, August.

23. Amente T, Tesfaye T, Addise M (2017) Contraceptive Use and Family Size Preferences in Jimma Arjo District of Eastern Wellega Zone in Oromia, Ethiopia. Journal of Nursing and Health Sciences (3).

24. Bhandari GP, KC Premarajan, N Jha, BK Yadav, IS Paudel et al. (2006) Prevalence and determinants of unmet need for family planning in a district of eastern region of Nepal. Kathmandu Univ Med J 4(2): 203210.

25. Tim Adair (2007) Desire for children and unmet need for contraceptive among HIV positive women in Lesotho, A document prepared for review by United States Agency for International Development 32.

26. David Ojakaa (2008) Trends and determinants of unmet need for family planning in Kenya. The DHS Working Papers series 56.

27. Korra, Antenane (2002) Attitudes toward Family Planning, and Reasons for Nonuse among Women with Unmet Need for Family Planning in Ethiopia. Calverton, Maryland USA: ORC Macro. 
28. Bhattacharya SK, R Ram, DN Goswami, UD Gupta, et al. (2006) Study of Unmet Need for Family Planning among Women of Reproductive Age Group Attending Immunization Clinic in a Medical College of Kolkata. Indian Journal of Community Medicine 31(2): 4-6.

29. Khan S, S Bradley, J Fishel, V Mishra (2008) Unmet Need and the Demand for Family Planning in Uganda: Further Analysis of the Uganda Demographic and Health Surveys. Macro International Inc

30. Barman S (2013) Socio-economic and Demographic Determinants of Unmet Need for Family Planning in India and its Consequences. Research on Humanities and Social Sciences 3(3).
31. Imasiku ENS, Odimegwu CO, Adedini SA, Ononokpono (2014) DN Variation's inunmet need for contraception in Zambia. Does ethnicity play a role? J Biosoc Sci 46: 294-315.

32. Woldemichael G, Beaujot R (2011) Currently married women with an unmet needfor contraception in Eritrea. Profile and determinants. Can Stud Popul 38: 61-81.

33. Dejenu G, Ayichiluhm M, Abajobir AA (2013) Prevalence and Associated Factors of Unmet need for Family Planning among Married Women in Enemay District, Northwest Ethiopia: A Comparative Cross-Sectional Study. Global Journals Inc (1): 22-32.

Your next submission with Juniper Publishers
will reach you the below assets
- Quality Editorial service
- Swift Peer Review
- Reprints availability
- E-prints Service
- Manuscript Podcast for convenient understanding
- Global attainment for your research
- Manuscript accessibility in different formats
( Pdf, E-pub, Full Text, Audio)
- Unceasing customer service
Track the below URL for one-step submission
https://juniperpublishers.com/online-submission.php

